\title{
Contributing to Fisheries Sustainability by Making the Best Possible use of Their Resources: The BEFAIR Initiative
}

\author{
Antonio A. Alonso ${ }^{1, *}$, Luis T. Antelo ${ }^{1}$, Irene Otero-Muras ${ }^{1}$, Raúl Pérez-Gálvez ${ }^{2}$. \\ ${ }^{1}$ Process Engineering Group. Instituto de Investigaciones Marinas, IIM - CSIC. \\ C/ Eduardo Cabello, 6. 36208 Vigo (Spain) \\ ${ }^{2}$ Chemical Engineering Department. University of Granada \\ Facultad de Ciencias y Edificio Politécnico. \\ Campus Universitario de Fuentenueva. 18071 - Granada (España) \\ * Corresponding Author. Phone: (+34)986231930 (Ext 251), Fax: (+34)986292762 \\ Emails: antonio@iim.csic.es (Antonio A. Alonso - Corresponding Author); \\ ltaboada@iim.csic.es (Luis T. Antelo); ireneotero@iim.csic.es (Irene Otero-Muras); \\ rperezga@ugr.es (Raúl Pérez-Gálvez)
}

\section{SUMMARY}

The global harvesting of marine products has increased from around 17 million tons in the 1950s to a current average amount of 85 million tons. The Food and Agriculture Organization (FAO) estimates that an annual average of 27 million tons of non targeted species are caught and thrown back into the sea, what means that near third of the fish volume captured every year is wasted. This in itself represents a purposeless waste of valuable living resources, but in addition, the large amounts of organic waste thrown into the sea may produce severe adverse effects on the ecological equilibrium of marine communities.

In this context, the BE-FAIR initiative ${ }^{1}$ (www.befairproject.com) -co-founded under the LIFE Environment Program of the European Union- was devised in the intention to contribute to a responsible and sustainable management of fisheries by making the best possible use of the captured resources avoiding its waste.

\footnotetext{
${ }^{1}$ Bentgn and Environmentally Friendly fish processing practices to provide Added value and Innovative solutions for a Responstble and sustainable management of fisheries. (LIFE05 ENV/E000267-BE FAIR) The Project consortium is constituted by: IIM-CSIC, Centro Tecnológico del Mar - Fundación CETMAR, Hermanos Rodríguez Gómez S.L., Espaderos del Atlántico, Peixesport S.L, Autoridad Portuaria de Vigo, Instituto de Investigaçao das Pescas e do Mar (IPIMAR) and Institut Français pour l'Exploitation de la Mer (IFREMER).
} 
This paper discusses the main actions taken in the project, which in the purpose of reducing the costs associated to the implementation of that so-called zero-discard and zero-waste policy, were directed to the development and implementation of integral management and novel processing practices. The aim of these actions is to up-grade captured resources (bycatch and wastes produced by fish processing) and thus to obtain added value products of interest in the food industry.

Keywords: By-catch, Discards, Integral Management, Valorisation Processes, Zero Waste, Food industry

\section{INTRODUCTION}

Estimations of fish captures by the FAO Fisheries Resources Division indicate an annual increase of $6 \%$ in the decades between 1950 (around 20 million tons) and 1970 (around 60 million tons), to reach an average figure of about 85 million tons (FAO, 2005), which remains stable since the $90 \mathrm{~s}$, owed to a progressive exhaustion of the fish living resources in combination with a increasing fishing effort. This corresponds to the $70 \%$ of total fish production, being the remaining $30 \%$ of fish produced by aquaculture. Such trend has undergone a sharp increased which has offset the lack of ocean fish captures. In this framework, scientists and fishery authorities have increased their efforts to improve the selectivity of the fishing gear as well as to provide a better utilization of the whole volume of catches. Nowadays, fishing vessels do not retain the total amount of catches for sale since they usually include undersized individuals with low commercial value or non-targeted species (by-catches) which are normally thrown back into the sea. This portion of the catch which is returned to the sea is referred to as discards. The percentage of discards is nonhomogeneously distributed among the different fishing fleets (trawlers, long-liners, etc.) as it 
mainly depends on the selectivity of the fishing gears employed. In fact it can be as large as 27 million tons per year according to some preliminary estimations of the FAO, what would represent near a third of the total fish captures. More conservative estimations (Kelleher, 2005) indicate that discards, in average, represent about the $8 \%$ of the total catches which gives a figure of around 7.3 million tons of fish species being discarded yearly (during the period from 1992 to 2001). Nowadays it becomes evident that discard practices represents a purposeless waste of valuable living resources, playing an important role in the depletion of fish populations. Regarding trawl fisheries, nearly all fish, including about half of the noncommercial crustaceans and $98 \%$ of non-commercial cephalopods are dead when discarded (Bozzano and Sardà, 2002).

It must be also noted that by discarding juvenile fish, fish of little or none economic interest or those which are over-quota, future yields (and hence incomes) are being lost. The discard of mature fish both waste resources in the short term and reduce the amount of adult fish which would otherwise support future productivity (Jensen et al., 1988).

Furthermore, continuous discarding in the same fishing area may produce a number of adverse ecological impacts due to ecosystem changes in the overall structure of trophic links and habitats that could risk the sustainability of fisheries (Bozzano and Sardà, 2002; Kelleher, 2005). The effect on the trophic web is still poorly understood nowadays, what calls for a better knowledge and a more exhaustive evaluation of the impact of discarding practices on marine ecosystems. Several authors (Polis and Strong, 1996; Groenewold and Fonds, 2000) have reported that this subsidiary input of organic matter and energy increases the abundance of consumer species, in detriment of the ecosystem equilibrium owing to a number of cascade effects throughout the trophic web (Tsagarakis et al., 2008).

Likewise, another source of residues and consequently of biomass losses, is that derived from fish processing activities. In particular, fish evisceration and cleaning also generates 
considerable amounts of wastes such as heads, bones, guts, skins, etc. Demersal species (e.g. monkfish, cod, conger, haddock, lings, etc) as well as cartilaginous species such as sharks are traditionally gutted on board, generating variable amounts of fish wastes (mostly composed of viscera) which are generally dumped at sea. In addition to its adverse effect on the trophic chains, this practice may contribute to the accumulation of pollutants as PCBs, dioxins or heavy metals as pointed out by several authors in recent articles (Mackenzie et al, 2004; Rainbow, 2007; Polak-Juszczak, 2009) or to the spread of parasites present in the viscera (as it is the case of anysakis) in the fishing areas (Blanco et al., 2006). The percentage of residues produced on-board varies widely since it depends on the target species (e.g. while white fish is processed, blue fish species are landed as whole fish), fishing fleets and areas (for instance, fishing fleets sailing in coastal waters will land the whole volume of captures to be processed in-land). Nevertheless, average waste amounts could range between $15 \%$ and $30 \%$ of the total catch, although in some instances it may increase up to the $80 \%$ as in the case of skate fish, for instance.

It is in this context, and in the aim of promoting the responsible and sustainable management of the European fishing activity, that the European Commission took a number of actions oriented to the implementation of "no-discard" and "zero-waste" policies to be followed by the European fishing fleets in the near future. In particular, actions were directed to the development of policies "to reduce unwanted by-catches and eliminate discards in European fisheries", as well as to make "the best possible use of the captured resources avoiding its

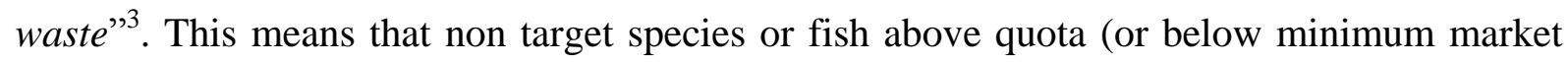
size) will be no longer discarded, but kept on board to be brought ashore. The implementation principles of this policy were discussed with Member States in 2007 and received the approval of the EU parliament in 2008. The first measures concerned two pilot fisheries: a)

\footnotetext{
${ }^{2}$ Communication from the commission to the council and the European parliament (28.3.2007), COM(2007) 132 final

${ }^{3} \mathrm{EC}$ communication on the reform of the CFP, Section 3.1
} 
the Nephrops trawling fishery in the ICES area VII and, b) the flatfish trawling fishery in the ICES areas IV and VIId. Final regulations are expected to come into force by 2010, although a number of measures oriented to a progressive reduction of discards are planned in the meantime.

The BEFAIR initiative -co-funded under the LIFE Environment Program of the European Union- has been set up in the intention of providing support to the above mentioned EU actions. In this way, the project objective aims at contributing to the minimization of the adverse ecological and environmental impact of fishing activities (on board as well as on shore), by helping fleets to comply with the so-called "zero-waste" production on board.

To that purpose, a number of state of the art technologies to upgrade wastes and discards so to obtain added value products, were explored at a pre-industrial scale. The list of possible products is as diverse as the industrial sectors that would benefit from the valorization alternatives. Discards and viscera could be good sources for fish meal, protein hydrolizates, peptones, enzymatic mixtures or fish oil with a high content of unsaturated fatty acids, being these products of interest in sectors such as aquaculture and food. Fish meal has been used as a livestock feed for many years, due to its high content in essential amino acids such as lysine, which is often deficient in grain products that are the typical base for most animal feeds (Hall, 1992). Kristinsson and Rasco (2000) have extensively reviewed the functional properties of fish hydrolyzates, such as emulsivity and foam stability, which make them suitable to be added to a wide range of functional products such as enteral formulas, protein supplements or beverages. So far, fish oil has been intended for aquaculture since it is an essential ingredient in the diet of carnivorous species (Tacon et al., 2008). Recent improvements on deodorization and stabilization processes have spread the incorporation of fish oil into food products and beverages for human consumption (Rubio-Rodríguez et al., 2010). Also, fish skin or cartilage from some species could be excellent raw materials for products as gelatine or chondroitin 
sulphate with applications in the food, cosmetic and pharmaceutical sectors (Blanco et al. 2006). From this perspective, most activities in the BEFAIR project concentrated on the assessment, development and implementation of efficient and integral waste management and processing practices both on-board (fishing fleets) and in-land (fish auctions) to recycle and to reuse wastes produced by the fishing industry, including discards and by-catch. In particular, two main lines of action have being pursued during the project life:

- The definition of viable management and processing practices for discards, by-catch and wastes so to recover and to produce valuable chemicals of interest in the food, cosmetic or and pharmaceutical industries.

- The validation of the approach at the pre-industrial scale by designing and constructing demonstration prototypes of up-grading processes to produce added value products as the ones mentioned above.

The purpose of this contribution is to describe the different actions taken in the project and give an outline of the main results obtained so far. The actions covered the whole up-grading cycle including waste conditioning, assessment of up-grading processes and prototype design and construction. Waste conditioning, to be presented in Section 2, includes classification and storage on the one hand, and design of the pre-treatment processes on the other, in order to maintain, what now would become a raw material, in the best possible conditions for upgrading. The systematic employed to select the up-grading processes as well as the conceptual design of the processes will be presented in Section 3. This action includes a complete technical and economic viability study (including operation and equipment costs) of the different processing alternatives potentially applicable to a given waste class and production volumes. Finally in Section 4, some details will be given on design and construction aspects of pre-industrial flexible and multipurpose processing plant prototypes adapted to the waste nature and seasonality. 


\section{WASTE CLASSIFICATION AND PRE-TREATMENT}

Waste management on-board, including waste classification, storage and pre-treatment is a crucial step in the whole valorisation cycle to the point of conditioning the viability of the integral up-grading approach. Keeping wastes (including discards) stored in the best possible conditions will prevent in as much as possible, deterioration of what is going to become raw materials for the valorisation processes. In the same way, carrying out a previous classification and separation of residues such as skins, bones, livers etc, which are precursors of added value products such as gelatines, chondroitin sulphate or fish oil (or squalen), respectively, will facilitate processing, maintaining quality and reducing operation costs.

Opportunities for implementing management and pre-treatment practices rely at a high extent on the type of fishing fleet and the fishing area considered. Essentially, vessel storage capacity is the limiting variable which will determine whether a given processing equipment can be installed or not, or under which conditions some classification protocols can be carried out on-board. This variable is so critical that in many instances refrigeration becomes the only reasonable alternative for waste materials until land is reached. It must be noted that, in general, storage capacity is an expensive asset usually reserved for the storage of the targeted species. Therefore, enforcing a zero-waste policy necessarily requires a readjustment of the cost-benefit balance. Although the analysis of the economic effects of the policy are out of the scope of this project, we hope to contribute to a sustainable solution by proposing alternatives which will add economic value to the wastes while at the same time will reduce the costs associated to storage capacity and transportation.

At this point, it must be stressed the necessity of controlling the levels of pollutants present in what is now considered a raw material, specially in applications oriented to aquaculture or food industry. The levels of organic pollutants or heavy metals will be highly dependent on 
the fishing area (geographic origin), type of species or tissue, and this should be taken into account when assessing the viability of a given up-grading alternative. In this way, and in addition to a sustained control of pollutant levels in the diverse materials, currently available pollutant removal technologies such as those based on activated carbon or supercritical extraction (Kawashima et al, 2009) should also be considered as part of the valorization process.

Next let us present two examples of possible pre-treatment processes namely fish oil extraction and water reduction that will partially help to reduce waste storage capacity while preserving quality deterioration of biomass.

1. Fish oils extraction: Livers contain considerable quantities of oil (between $40 \%$ and $75 \%$ depending on the specie considered), often enriched in squalen (35-60\% of the total oil). Squalen is used as a health-food or is refined to squalen, a product used in pharmaceuticals and cosmetics (Claeys-Bruno et al., 2008). The process to obtain these oils includes the separation of livers from visceral residues of chondrichtyes, grinding and pressing the organs and centrifugation to separate the oils. Finally, solid residues will be kept frozen and oil stored for refining with stabilization additives to avoid oxidation. Optionally, previous cooking of the wastage to $85-95{ }^{\circ} \mathrm{C}$ will produce protein coagulation thus facilitating the separation of the water and oily phases, although at the expenses of a drastic reduction of oil quality. Depending on the characteristics of the oil, it could be stored to be used in aquaculture or food industry, or it can be processed to produce bio-fuel.

2. Volume reduction: The future application of a non-discard policy on fishing vessels will increase the volume of marine materials to be stored on board, and thus the energy and space requirements. Those fractions containing discards and wastes, and not intended to any upgrading process (fish eyes, skins, livers, etc) may be subject to a volume reduction process. The objectives pursued are: 
- The minimization of the volume of solid by-products stored on-board and thus, the energy and space requirements for storage (refrigerated or frozen).

- The microbiological stabilisation of these wastes. A lower water activity reduces the rate of quality loss, increasing the self-life of the resulting cake.

- The recovery of valuable fractions, such as proteins and fish oil for further up-grading operations.

Note that the effluents generated on board should undergo a suitable depuration treatment prior to their discharge to the sea in order to minimise their environmental impact. Proteins could serve as raw materials for silage, hydrolizates, or peptone production. Fish oil could be stored for refining or bio-fuel as explained before.

The proposed volume reduction process essentially follows a procedure similar to that applied to the production of fish meal (Bimbo, 1990). Fish discards are cut and fed with the help of a belt conveyor into a mechanical press, where it undergoes a multiple stage pressing operation in order to obtain a partially dewatered cake (which represents around the $80-90 \%$ of the original wet weight of the raw material), with a reduction in volume of $50-60 \%$ and a press liquor comprising several phases (oil, water, blood and suspended solids) with a high organic load (COD 80-120 g. $\mathrm{O}_{2} / \mathrm{L}$ - Afonso and Borquez 2002). The press liquor bears an organic load above the maximum discharge limits established for the fisheries wastewaters, so an effluent treatment section constitutes a critical part of the process as it must minimize the adverse environmental impact of the press effluent. It consists of several microfiltration steps (filter cartridges with rating size $250 \mu \mathrm{m}$ and $465 \mu \mathrm{m}$ ) able to remove up to $28.4 \%$ of suspended solid particles and $43 \%$ of the protein content from the press liquor, followed by centrifugation to recover the fish oil. Nevertheless, this filtration step only entails $5.6 \%$ of COD removal, which indicates that most of the oxidising species (mainly proteins) are present in the form of soluble compounds. In order to remove these compounds of lower molecular 
weight, a final ultrafiltration step was proposed, based on ceramic membranes (which present better resistance to fouling formation and corrosion by cleaning agents). These are able to retain up to $88 \%$ of proteins of the bulk solution (retentate stream) and render a final filtrate with a low organic load (COD 3-9 g. $\mathrm{O}_{2} / \mathrm{L}$ ) which can be directly discharged to the sea.

\section{VALORISATION PROCESS ASSESSMENT}

A set of well established technologies and methods from chemical and process engineering have been combined on a systematic way to develop and to demonstrate the possibilities of fish residues and by-products up-grading to obtain valuable products of interest in food and pharmaceutical industry. Among those methods and technologies, a number of state of the art processes have been considered. In particular, special attention has been paid to the following valuable products and their corresponding production processes:

Chondroitin sulphate $(\boldsymbol{C S})$ : This chemical is used as a dietary supplement to maintain the structure and function of cartilage (referred to as chondroprotection, Pipitone 1991), to relief the pain caused by osteoarthritic joints (Kerzberg et al. 1987) and as an antiinflammatory (Ronca et al. 1998).

For reasons quite related with recent animal diseases (as the recent cases of mad cow disease or avian influenza), the production of CS from fish cartilage offers new market opportunities as compared with that obtained from bovine or avian livestocks. The process considered in the framework of the BE-FAIR Project is partially based on the one proposed by Lignot et al. (2003) and consists on the following steps:

1. A hot water treatment of chondrichtyes residues, and pulverization of the cartilage thus obtained.

2. Enzymatic hydrolysis of the cartilage. Separation of a solid residue and a clarified hydrolysate. 
3. Alkaline hydroalcoholic treatment of the hydrolysate, with precipitation of chondroitin sulphate and solubilisation of proteins in the supernatant.

4. Redisolution and neutralization of the sediment, and separation by centrifugation of the insoluble protein residue.

5. Concentration by ultrafiltration, followed by diafiltration to eliminate saline content and the remaining low molecular weight solutes.

6. Drying of the concentrate and grinding.

Fish gelatine: Gelatine is obtained by the hydrolysis of collagen which is the principal protein found in skin and bones. A complete review of the state of the art of fish gelatine production processes (starting by the work of Grossman and Bergman 1992) can be found in a recent paper by Kareem and Bhat (2008). The process we have considered to obtain this product from fish skins (Nicolas-Simonnot et al. 1997) can be summarized as follows:

1. In order to prepare the raw material, skins are washed on sodium hydroxide, sulphuric acid and citric acid solutions.

2. Thermal collagen extraction in temperature ranges from $40-45^{\circ} \mathrm{C}$ up to $80{ }^{\circ} \mathrm{C}$ and residence times between 8 to 10 hours.

3. Purification of the product either by ultrafiltration or evaporation, and final drying to achieve the desired humidity of the product.

Hyaluronic acid $(\boldsymbol{H A})$ : This valuable chemical with anti-inflammatory and anti edematous properties (see Gemeiner et al. 2007 for a complete review regarding HA and its applications) was conventionally extracted from animal tissues and now is increasingly produced by microbial fermentation (Fong Chon et al. 2005, Chen et al. 2008). These methods provide low production costs and more efficient purification. Alternative sources include fish vitreous humour as suggested by Murado et al. (2005). In the BE-FAIR Project, this valorisation process to get HA from a fish waste (eyes) is considered. 
After extraction and concentration by ultrafiltration of the vitreous humour collected from the eyes, the process includes the following steps:

1. Alkaline hydroalcoholic treatment at low temperature, with precipitation of sodium hyaluronate and solubilisation of proteins in the supernatant.

2. Redisolution and neutralization of the sediment, and separation by centrifugation of the insoluble protein residue.

3. Concentration by ultrafiltration, followed by diafiltration to eliminate saline content and remaining low molecular weight solutes.

4. Ethanol precipitation (repeated if necessary) of the ultrafiltration retentate.

\section{THE VIRTUAL PLANT ENVIRONMENT}

Before carrying out the proposed valorisation technologies to a productive industrial scale, and as an action of the BE-FAIR Project, an efficient user-friendly dynamic and multipurpose visual interface for the simulation of food and biotechnology processing plants (Taboada et al. 2003; Vilas et al. 2004) was developed on EcosimPro (www.ecosimpro.com). This environment is a powerful mathematical tool capable of solving dynamic systems represented by differential-algebraic equations (DAE) with symbolic, numeric methods and discrete events handling capacities. EcosimPro provides an object-oriented non-causal approach towards creating reusable component libraries. By taking advantage of the cited EcosimPro's capabilities, most common components of processing plants were developed, and included in libraries which constitute the building blocks on which virtual representations of processes are based (see Figure 1 for an example).

Due to the structure of the environment, inclusion/exclusion, modification or improvement of both existing and new components can be done in a straightforward manner. This virtual scenario allows the user to predict and to analyze possible changes on the product (quantity 
and quality) as well as possible operational problems caused by given input variations (quantity and quality of raw material), variations over operational parameters (for instance, $\mathrm{pH}$ or temperatures, variations on the recycled fraction, etc.) or over the equipment scaling (unit volumes).

\section{The Gelatine Process}

As a representative example of the capabilities offered by the virtual environment for modelling and improving existing valorisation processes, a model library with the most representative processes in gelatine production from fish skin has been created.

As briefly presented in the previous section, fish skin is a good source of collagen, the precursor of gelatine. Collagen is insoluble in water, but its fibers shrink at hot temperature producing water soluble gelatine. The core of the gelatine production process consists basically on the extraction of the denatured collagen macromolecules from the skin of both ray finned fishes (cod, tuna, pollock, etc.) and chondrichthyes (namely shark and ray) to an aqueous solution. Variations in the operation conditions of the process, at a high extent dependent on the characteristics of the raw material and the desired product quality, can be devised on a straightforward manner in the virtual plant environment.

The main steps on the fish gelatine process are:

1. Pre-treatment of the raw material: It is known that alkaline and/or acid pre-treatments before extraction are critical for final yield and strength of the gelatine extracts, but the possible mechanism and the effects of these pre-treatments are still poorly understood. According to Zhou and Regestein (2005), the extent of gelatinization and gel strength depend on the cross linkages present in the collagen. In this sense, the purpose of the pre-treatment is twofold: on the one hand, removing unwanted material such as noncollagenous proteins and soluble solids with minimum collagen loss and, on the other 
hand, destroying certain cross-linkages present in the collagen with less breakage of peptide bonds.

The pre-treatment section of the fish gelatine process is characterized by a high water consumption what critically conditions the overall operation cost and thus the viability of the process. In this sense, water saving by means of recycle policies can be crucial in improving the efficiency of the process, as it will be shown later in this work.

2. Extraction: Depending on the pre-treatment sequence, the extraction can be carried out in acid, neutral or alkaline medium, giving rise to gelatines with different molecular weight distribution (Zhou and Regestein 2006). Gelatine quality is evaluated on the basis of several functional properties like gel strength, viscosity, solubility, turbidity, melting and gelling point (Choa et al. 2004), affected by many factors including the molecular weight distribution. Gelatine is made up of a series of polypeptide chains, where the so-called $\alpha$-chain, with a molecular weight of 95,000 $\mathrm{g} / \mathrm{mol}$, acts as the basic element which will determine the molecular weight (NicolasSimmonot et al. 1997). The $\mathrm{pH}$, the temperature and the time of operation will affect to the rate and extent of the extraction, but also to the degradation of the gelatine chains, so their control become critical at the extraction stage.

3. Purification: The purification process is devoted to transform the solution resulting from the extraction into a product with the required specifications. In terms of micro constituents, the desired properties are obtained by means of treatments such as activated carbon filtering, oxidation and/or deionization whereas the specifications in terms of water content require the concentration and drying of the gelatine solution. In the conventional process, the gelatine solution, with an initial concentration of 3 $5 \%$, is filtered and fed into a triple effect evaporator to concentrate up to $35 \%$, followed by a drum drying to obtain a final product with $85-90 \%$ gelatine. 
Evaporation can remove about $80-85 \%$ of the water but it is energy intensive and very sensitive to scaling of fuel costs (Chakravorty and Singh 1990). This drawback can be overcome by employing ultrafiltration as an initial step in the dewatering of gelatine liquors. The high molecular weight of gelatine (with an average of 50 to $70 \mathrm{kDa}$ ) makes it suitable for pressure driven separation techniques at moderate applied pressures. Ultrafiltration presents three main advantages upon conventional processes (Simon et al. 2002): i) energy consumption is at least $40 \%$ lower than those required for evaporation, ii) thermal degradation in gelatine molecules is minimized as pressure-driven processes are undertaken at room temperatures and iii) the final product presents higher purity due to the removal of inorganic compounds (mainly salts from pre-treatment step) with molecular weight below the membrane nominal cut-off.

Permeate flux is strongly dependent on gelatine concentration, which limits practical UF to about $20 \%$ gelatine in the final product (Cheryan 1998) due to the appearance of a concentration polarisation layer which limits the passage of permeate through the membrane pores, so ultrafiltration must be completed with a single effect evaporation and drum drying to obtain the final dry powder.

For the case of fish gelatine process, a library of units was developed in EcosimPro in order to construct the virtual plant which reproduces the original process (See Figure 1 - Zoom Window):

- Washing_Unit: An EcosimPro component has been designed including the mass balance equations for the washing unit. It communicates with the environment by a number of physical ports: a) the skin inlet, b) the solvent inlet, c) the extract (containing the solid phase), and d) the purge (constituted by the liquid phase plus the rest of skin, lost during the operation). The composition of the solvent can be selected among three different 
possibilities consisting of a solution of sodium hydroxide, sulphuric, or citric acid. The internal water recycle is also selected by the user. As mentioned, the procedure in gelatin pre-treatment requires a given sequence of washings, aiming at the optimization of the quality and yield of the final product. The washing unit offers the possibility of connection with another component, the Dispenser component, also included in the library, which computes and dispense the amount of solvent with the appropriate concentration of reactive so to fulfil the proposed recipe.

- Extraction: The EcosimPro component designed for the extraction unit is communicated with the environment through four physical ports: a) the skin inlet (containing a given fraction of extractable gelatine), b) the solvent inlet, c) the extract (containing the solid phase) and d) the gelatine solution outlet. The temperature and $\mathrm{pH}$ of operation can be fixed by the user (then the program calculates the temperature and concentration of the solvent), or computed from the solvent characteristics, depending on the option selected (design or simulation approach). In addition, the regime of operation can be selected between continuous or batch.

- Ultrafiltration: For modelling this purification process, batch operation is preferred since it requires minimum membrane area (Cheryan, 1998). The permeate stream can be partially or fully returned to the feeding tank for a subsequent batch. For this purpose, different EcosimPro components (tank, membrane, stream mixer and splitter) were created and equipped with physical (flow and solvent concentration) and signal ports (level and flow control) which enable the user to choose between different operational configurations (batch /continuous operation, partial/full recirculation of the retentate, diafiltration, etc).

In order to illustrate the possibilities offered by the virtual environment, we present next two case studies related with the fish gelatine process:

\section{Case 1: Analysis of water recycle policies in the pre-treatment section.}


This pre-treatment can be configured by connecting, as shown in Figure 1, series of washing units with the so-called dispenser units, which add the required amount of reactant to carry out the washing step (alkaline, acid, etc.). In this case, two alkaline, strong and weak acid washing steps were considered with water washings inserted between each type of pretreatment. Once the washing section model was configured using the design approach (that is, in agreement with a given set of operation conditions, the system computes the proper amounts of reagents), and under the assumption of $1,000 \mathrm{~kg}$ of fresh fish skin entering the process for treatment, two experiments are created: a) The first one considers the scenario of a washing section without any water recycle on the units, and b) the second one introduces a recycle of the $30 \%$ of the liquid leaving each washing unit. It can be stated that, for equal product requirements, savings for the considered scenario with a $30 \%$ of recycle are significant, both in terms of water consumption as well as in terms of reactants savings:

1. $25.14 \%$ for the sodium hydroxide (from 0.83 to $0.62 \mathrm{~kg}$. consumed - recycle-no recycle, respectively).

2. $25.16 \%$ for the citric acid (from 4.81 to $3.60 \mathrm{~kg}$. consumed).

3. $23.31 \%$ for the sulphuric acid (from 0.80 to $0.61 \mathrm{~kg}$. consumed)

These results can be translated on a lower plant operation cost.

\section{Case 2: Improvement of the extraction process.}

For the developed Extraction unit, the model considers two simultaneous phenomena taking place: The extraction itself and the degradation of the gelatine, that is divided into four main categories of macromolecules $\left(F_{1}\right.$ to $\left.F_{4}\right)$ attending to the molecular weight (from higher to lower). The objective pursued in this case was to define operation conditions, namely extraction temperature, $\mathrm{pH}$, residence time and number of extraction steps, to optimize the efficiency of the extraction process. Optimization must be understood in the sense of 
maximizing yield (amount of gelatine extracted) while ensuring a minimum quality (related with the molecular weight fractions).

We consider a scenario where a batch of $1,500 \mathrm{~kg}$ of wet skin with a $5 \%$ of gelatine are treated into a single Extractor unit at $\mathrm{T}=60^{\circ} \mathrm{C}$ and $\mathrm{pH}=3$. As shown in Table 1, the extent of the extraction increases with the time of treatment but the quality of the extracted gelatine, related with the fraction of higher molecular weight $\left(\mathrm{F}_{1}\right)$, decreases nearly a $60 \%$, which clearly affects the quality of the final product.

Alternatively, the given batch $(1,500 \mathrm{~kg}$ of wet skin with $5 \%$ gelatine) was processed on a train composed by four extraction units. Simulation results revealed for this configuration a considerable increase in the yield of high quality gelatine $F_{1}$ after 10 hours operation (1.640 $\mathrm{kg}$. versus $0.352 \mathrm{~kg}$ obtained on a single extractor), without a significant loss in the fraction of gelatine extracted $(87.5 \%$ versus $95.5 \%)$.

\section{PRE-INDUSTRIAL PROTOTYPING}

As mentioned in the introduction, the final goal of the BE-FAIR Project is the design and demonstration of different prototypes capable of integrating the different valorization processes considered, by making the best possible use of the technologies and equipments currently at hand, while respecting the existing constraints on available space (for instance on board fishing vessels) or environmental impact (either associated to raw materials or to their processing). Details on the scale and characteristics of the designed pre-industrial prototypes are given next:

1. A flexible multi-purpose plant, which shares equipment to be employed for gelatin and chondroitin sulphate production. An automatic control system allows the flexible operation of the plant. This fact drastically reduces both the equipment and instalation costs as well as the space needed to place the complete plant. A picture of the 
multipurpose pre-industrial prototype is presented Figure 2. It consists of the following three main sections:

- Reaction section: It includes the jacketed stirred reactor, a decanter, a mixer, reactants dispensers and several washing-products/liquid-wastes storage tanks. For chondroitin sulphate $(\mathrm{CS})$ production, a centrifuge is needed to separate the CS precipitate from the insoluble protein residue.

- Heating section: It consists mainly of a heater, the jacket which supplies heat to the reactor, and the hot water circuit.

- Control panel: The integrated processes are controlled with a dedicated PLC. The developed control system allows the operator to actuate over several aspects of the plant operation (flows, temperatures, etc.) through a simple and intuitive visual interface integrated in the supervision panel.

Concentration and purification steps are carried out on standard equipment for evaporation, drying and ultrafiltration. As shown in Table 2, the processing capacities and yields depend on the target compound to be produced in the plant.

2. A water volume reduction prototype designed to operate on-board fishing vessels. It will be used to reduce the water content of discards and fish wastage and thus the volume of the resulting solid by-products to be stored. In addition, by reducing water activity, the self-life of the resulting cake will increase. The prototype includes an effluent treatment section to minimize the environmental impact of the compacting operation. The prototype built is shown in Figure 3, being its main parts the following:

- A grinding machine, where the raw material is pre-treated in order to obtain a better yield in the press. 
- A hydraulic press, where the raw material, usually by-catch species and wastes (guts, skins, etc.) resulting from fish processing activities undergoes a multiple stage compacting treatment. As the result of pressing operations, two streams are obtained: a partially dewatered cake with a volume reduction of up to $50 \%$, and a press liquor that can be drained to the sea. The cake must be either refrigerated $\left(4^{\circ} \mathrm{C}\right)$ or frozen $\left(-16^{\circ} \mathrm{C}\right)$.

- Two series filter cartridges, to recover oil residues and remove fine solids. This pre-treatment is needed in order to remove suspended particles from the bulk solution which could exhaust the membranes in the ulterior ultrafiltration stages. The cartridge consists of a cylindrical outer filter having an axial bore and a surrounding side wall structure, settled to allow the passage of the water into the axial bore and thus to retain fine solids. These fine solids can be added back to the press cake and stored on board.

- An ultrafiltration unit, where liquid effluents are treated to remove the remaining organic molecules (proteins, etc.), thus reducing their organic load up to an $88 \%$ in terms of protein retention. Ceramic membranes are preferred to the organic ones since they offer higher resistance to fouling formation and corrosion by cleaning agents. After this final treatment, the final permeate can be discharged into the sea without causing negative environmental effects.

All the units that are part in the fish compaction process were assembled in a compact prototype that is presented in Figure 3. This system makes use of the pneumatic system available on-board the fishing vessels (e.g. to haul the nets) what enables a better control of the operation parameters (pressure, compression speed, number of pressing steps). This prototype has a feed capacity of $8-10 \mathrm{~kg}$. per batch, with a maximum duration of 15 min per batch, which yields a processing capacity up to 40 
$\mathrm{kg} / \mathrm{h}$ of raw material. The diagram shown in Figure 4 summarizes the mass balances for each unit operation and the composition of each stream involved in the process.

\section{CONCLUSIONS}

One of the strategies towards a responsible management of fisheries is to promote policies of no-discard and zero-waste production both on-board of fishing vessels as well as in-land (ports, transforming industry, etc.). In order to ensure sustainability of fisheries and fishing related industry, such policies must be accompanied by up-grading strategies for the fish wastes and by-products. In this aim, the BE-FAIR initiative have been directed to the development and demonstration at a pre-industrial scale of an integral framework to make the best possible use of fishing resources by obtaining valuable chemicals of potential interest mainly in the food industry, but also in other sectors such as the pharmaceutical.

\section{Acknowledgements}

The authors acknowledge the financial support received from the European Union through the LIFE Environment Program of the European Union (LIFE05 ENV/E000267-BE FAIR).

\section{References}

Afonso, M.D. and Borquez, R. (2002). Review of the treatment of seafood processing wastewaters and recovery of proteins therein by membrane separation processes prospects of the ultrafiltration of wastewaters from the fish meal industry. Desalination, 142: $29-45$.

Bimbo, A., P., (1990). Production of fish oil. In: Stansby, M.E., editor. Fish Oils in Nutrition, pp. 141-180. Reinhold Publishing, New York, USA. 
Blanco, M. Sotelo, C.G. Chapela, M.J. and Perez-Martin, R.I. (2006). Towards sustainable and efficient use of fishery resources: present and future trends. Trends Food Sci. \& Tech., 18(1): 29-36.

Bozzano A. and Sardà F., (2002). Fishery discard consumption rate and scavenging activity in the northwestern Mediterranean Sea. ICES Journal of Marine Science, 59: 15-28.

Cheryan, M. (1998). Ultrafiltration and Microfiltration Handbook. Technomic, Lancaster, PA, USA.

Choa, S.M. Kwaka, K.S., Parkb, D.C., Gua, Y.S., Jia, C.I., Jangc, D.H., Leea, Y.B. and Kim, S.B. (2004). Processing optimization and functional properties of gelatin from shark (Isurus oxyrinchus) cartilage. Food Hydrocolloids, 18(4): 573-579.

Claeys-Bruno, M., Lamant, J., Blasco, L., Phan-Tan-Luu, R. and Sergent, M. (2008). Development of a skin care formulation using experimental designs Chemometrics and Intelligent Laboratory Systems.

In Press. doi:10.1016/j.chemolab.2008.03.010

Fong Chong, B., Blank, L.M., Mclaughlin, R. and Nielsen, L.K. (2005). Microbial hyaluronic acid production. Appl. Microbiol. Biotechnol., 66: 341-351.

Groenewold, S., and Fonds, M. (2000). Effects on benthic scavengers of discards and damaged benthos produced by the beam-trawl fishery in the southern North Sea. ICES Journal of Marine Science, 57: 1395-1406.

Grossman, S. and Bergman, M. (1992). Process for the production of gelatin from fish skins. US patent 5,093,474.

Hall, G.M., (1992). Fish processing technology. In: Ockerman, H.W. editor. Fishery byproducts, pp. 155-192. VCH publishers, New York, USA.

Jensen A. L., Reider R. H., Kovalak W. P., (1988). Estimation of production forgone. North American Journal of Fisheries Management, 8:191-198. 
Karim, A.A. and Bhat, R. (2008). Fish gelatin: properties, challenges, and prospects as an alternative to mammalian gelatins. Food Hydrocolloids. In press. Available on line: doi:10.1016/j.foodhyd.2008.07.002.

Kawashima, A., Watanabe, S., Iwakiri, R., Honda, K. 2009. Removal of dioxins and dioxinlike PCBs from fish oil by contercurrent supercritical CO2 Extraction and activated carbon treatment. Chemosphere 75: 788-794.

Kelleher, K. (2005). Discards in the world's marine fisheries, an update. FAO Fisheries technical Paper $N^{\circ}$ 470. Rome.

Kerzberg, E. M., Roldan, E. J., Castelli, G. and Huberman, E. D. (1987). Combination of glycosaminoglycans and acetylsalicylic acid in knee osteoarthrosis. Scand. J. Rheumatol., 16: $377-380$.

Kogan, G., Šoltés, L., Stern, R. and Gemeiner, P. (2007). Hyaluronic acid: a natural biopolymer with a broad range of biomedical and industrial applications. Biotechnology Letters, 29(1): 17-25.

Kristinsson, H.G. and Rasco, B.A., (2000). Fish protein hydrolysates: production, biochemical and functional properties. Critical Reviews in Food Science and Nutrition, 40: 43-81.

Lignot, B., Lahogue, V. and Bourseau, P. (2003). Enzymatic extraction of chondroitin sulfate from skate cartilage and concentration-desalting by ultrafiltration. J. Biotechnol., 103(3): 281-284.

Liu, L., Wanh, M., Du, G. And Chen, J. (2008). Enhaced hyaluronic acid production of Streptococcus zooepidemicus by an intermitten alkaline-stress strategy. Letters in Applied Microbiology, 46: 383-388.

Mackenzie, B.R., Almesjo, L. and Hansson, S. 2004. Fish, fishing and pollutant reduction in the Baltic Sea. Environ. Sci \& Technol. 38(7): 1970-1976. 
Murado, M.A., Montemayor, Mª I., López Cabo, M., González, Mª. P. and Pastoriza, L. (2005). Nuevo procedimiento de obtención de ácido hialurónico. Spanish Patent $\mathrm{N}^{\circ}$ 2192960.

Nicolas-Simonnot, M.O., Tréguer, V., Leclerc, J-P., Sardin, M., Brajoux, J-P., Moy, J. and Takerkart, G. (1997). Experimental study and modelling of gelatin production from bone powder: elaboration of an overall kinetic scheme for the acid process. Chemical Engineering Process, 67(1): 55-64.

Pipitone, V. R. (1991). Chondroprotection with chondroitin sulfate. Drugs Exp. Clin. Res., 17: $3-7$.

Polak-Juszczak, L. 2009. Temporal trends in the bioaccumulation of trace metals in herring, sprat, and cod from the southern Baltic Sea in the 1994-2003 period. Chemosphere 76, 1334-1339.

Polis, G. A., and Strong, D. R. (1996). Food web complexity and community dynamics. The American Naturalist, 147: 813-846.

Ronca, F., Palmieri, L., Panicucci, P. and Ronca, G. (1998). Anti-inflammatory activity of chondroitin sulfate. Osteoarthritis Cartilage, 6 (suppl. A): 14-21.

Rubio-Rodríguez, N., Beltrán, S., Jaime, I., de Diego, S.M., Sanz, M.T. and Carballido, J.R. (2010). Production of omega-3 polyunsaturated fatty acid concentrates: A review. Innovative Food Science and Emerging Technologies, 11 (1): 1-12.

Simon, A., Vandanjon, L., Levesque, G. and Bourseau, P. (2002). Concentration and desalination of fish gelatin by ultrafiltration and continuous diafiltration processes. Desalination, 144: 313-318.

Taboada, L.T, Villafin, M., Banga, J.R. and Alonso, A.A. (2003). Virtual Interface for Developing SCADA Tools for Chemical Process. II Ecosimpro User's Workshop, Madrid (Spain). Available on-line on www.ecosimpro.com. 
Tacon, A.G.J. and Metian, M. (2008). Global overview on the use of fish meal and fish oil in industrially compounded aquafeeds: Trends and future prospects. Aquaculture, 285: 146158.

Tsagarakis, K.,Machias, A., Giannoulaki, M., Somarakis, S., Karakassis, I. (2008). Seasonal and temporal trends in metrics of fish community for otter-trawl discards in a Mediterranean ecosystem. ICES Journal of Marine Science, 65(4): 539-550.

Vilas, C., García, M.R, Villafín, M., Banga, J.R and Alonso, A.A. (2008). Desarrollo de una librería de componentes en ECOSIMPro para la operación de plantas de procesamiento térmico de alimentos. Revista Iberoamericana de Automática e Informática Industrial, 5(1): $51-65$.

Zhou, P. and Regestein J. M. (2005). Effects of alkaline and acid pre-treatments on Alaska Pollock skin gelatin extraction. Journal of Food Science, 70(6): C392-C396.

Zhou, P. and Regestein J. M. (2006). Determination of total protein content in gelatin solutions with the lowry or biuret assay. Journal of Food Science, 71(8): C474-C479.

2

3

4

5

(6

\section{Figure Captions:}

Figure 1: Virtual environment generated on EcosimPro for designing the washing section of the fish gelatin process. In the zoom window, representative virtual process units developed to reporduce the fish gelatin process are depicted: a) Washing_Unit; b) Extractor; c) Ultrafiltration.

Figure 2: Multipurpose pilot plant prototype built to produce fish gelatine and chondroitin sulphate. Dimensions of the prototype are: $11.80 \mathrm{~m}(\mathrm{~L}) \times 2.15 \mathrm{~m}(\mathrm{~W}) \times 3.38 \mathrm{~m}(\mathrm{H})$ 
Figure 3: Water reduction prototype. Its dimensions are: $2.85 m(L) \times 0.85 m(W) \times 1.45 m(H)$

625

626

627

628

629

630

631

632

633

634

635

636

637

638

639

640

641

643

644

\section{9}

642

Figure 4: Processing capacities and composition of the volume reduction prototype. SS: suspended solids, P: proteins.

\section{Table Captions:}

Table 1: Extent and quality of final product for a single extraction unit (1,500 $\mathrm{kg}$ of wet skin 5\% treated at $T=60^{\circ} \mathrm{C}$ and $\mathrm{pH}=3$ )

Table 2: Processing capacities and valuable compound productions for the pre-industrial multipurpose plant prototype

3

4
6

7

38

(1) 41 43

\section{Figures:}




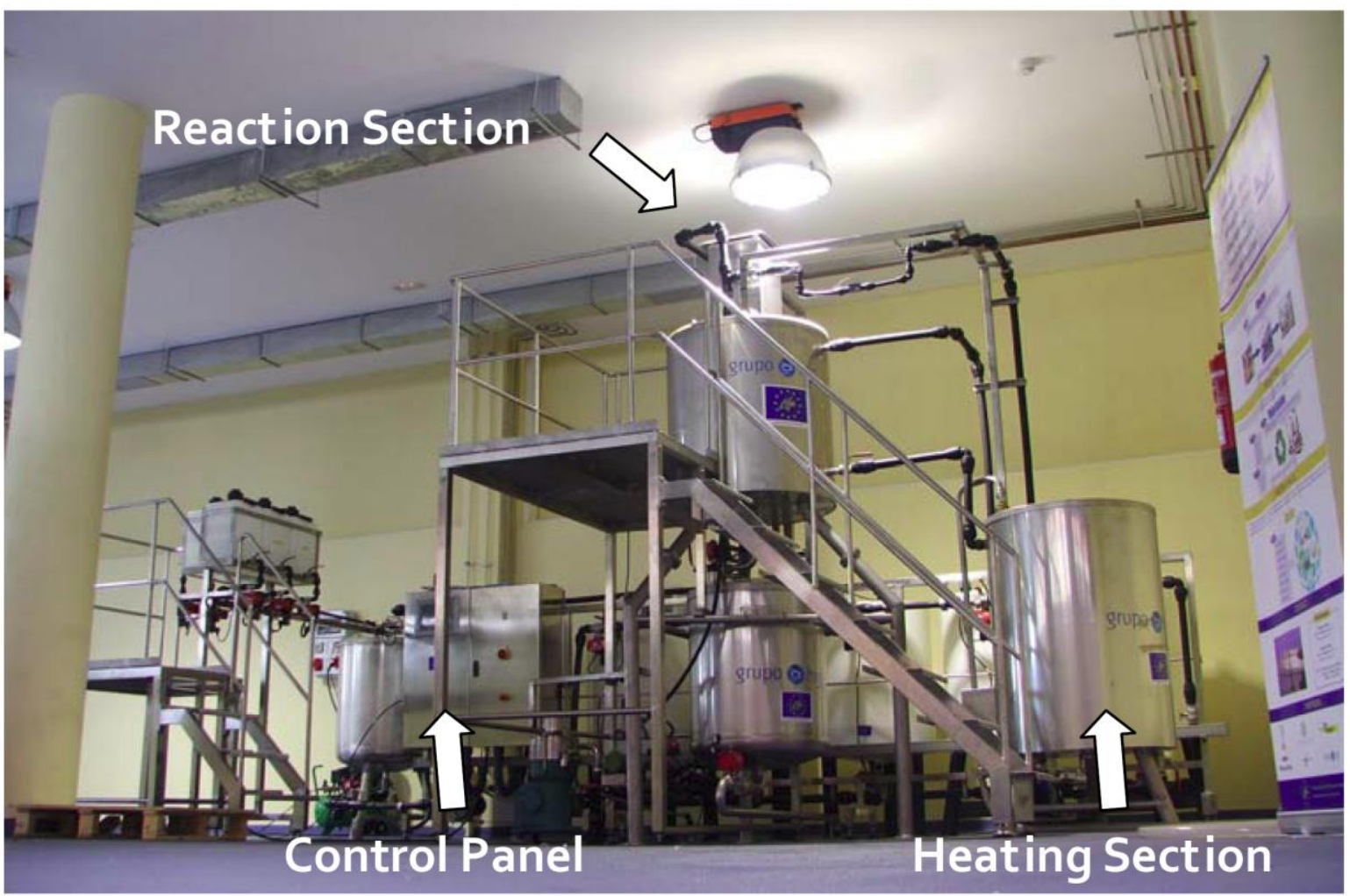

Figure 2 


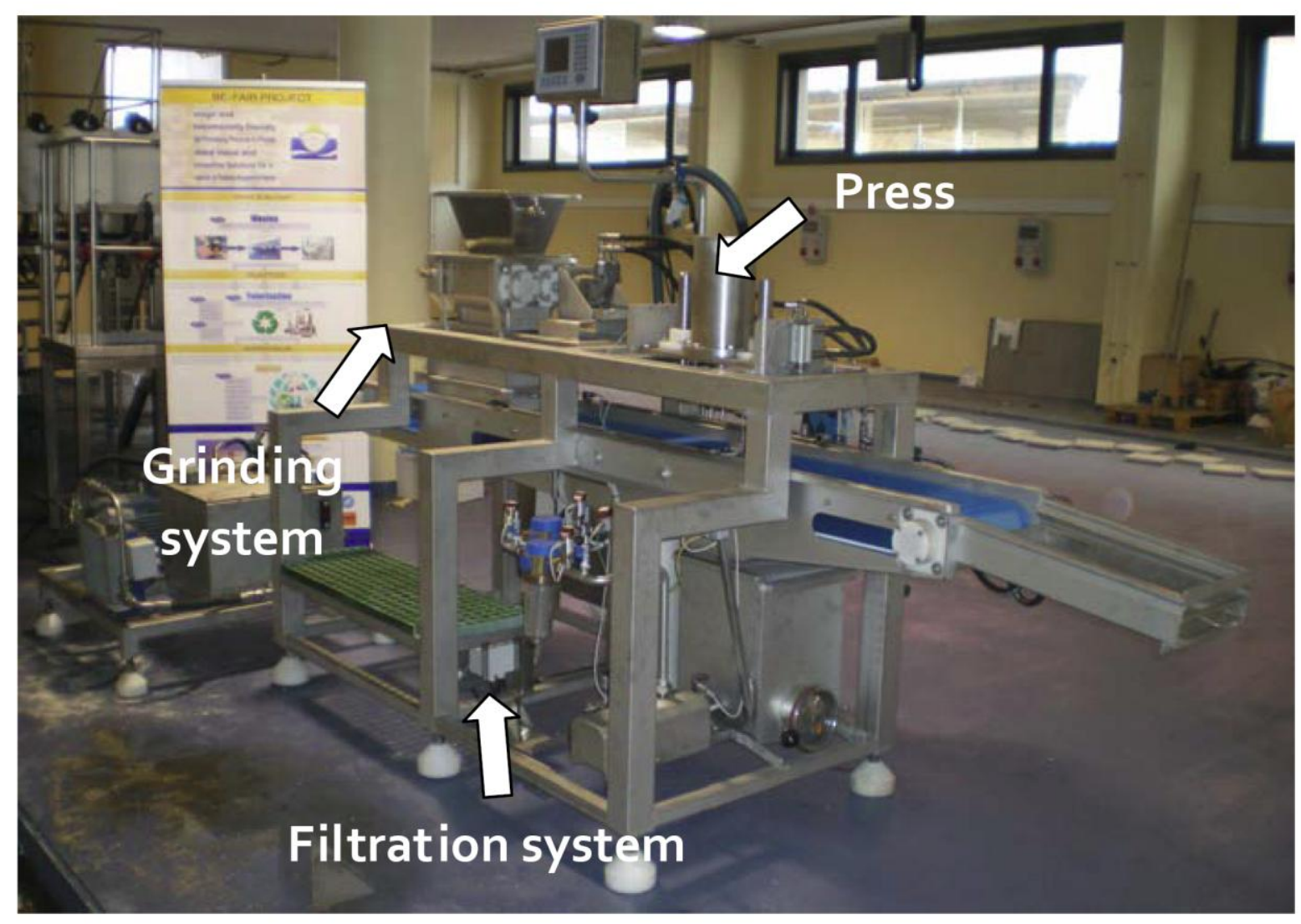

\section{Figure 3}




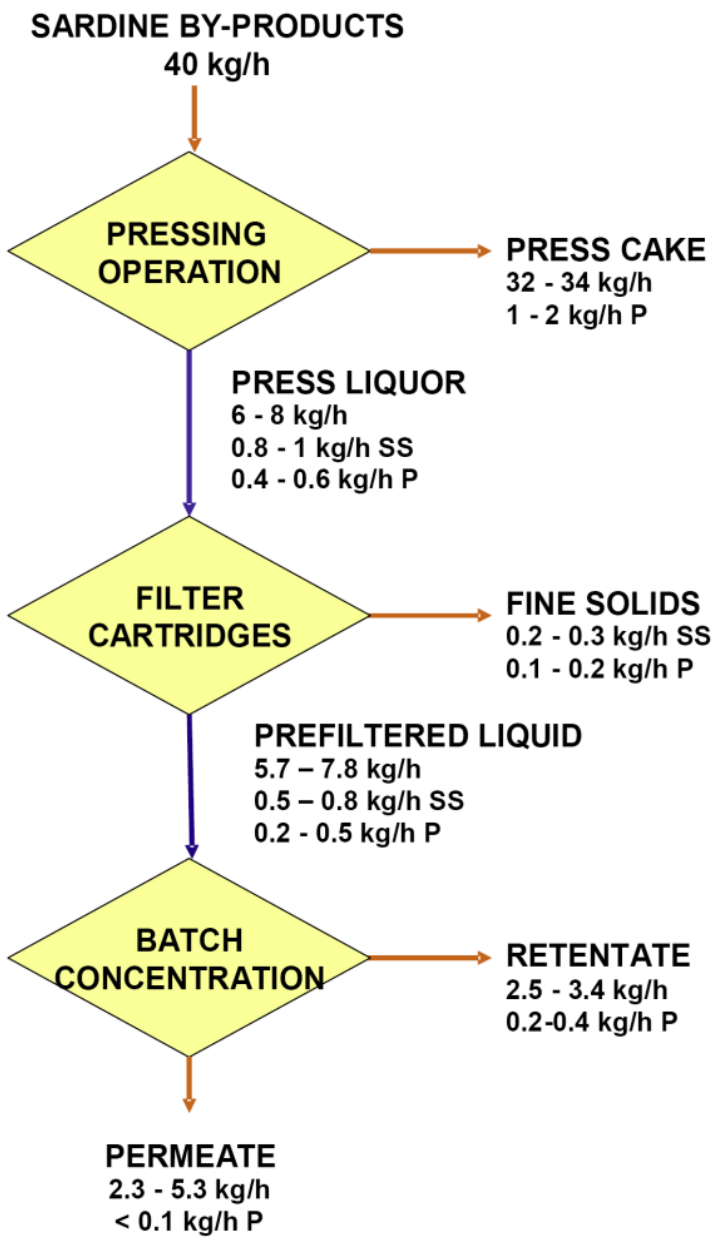

Figure 4

\begin{tabular}{|c|c|c|}
\hline Time (h) & Extracted Gelatine (\%) & $\mathbf{F}_{\mathbf{1}}(\mathbf{k g})$ \\
\hline 3.5 & 54.9 & $\mathbf{0 . 8 1 3}$ \\
5.5 & 81.3 & $\mathbf{0 . 7 3 0}$ \\
$\mathbf{1 0}$ & $\mathbf{9 5 . 5}$ & $\mathbf{0 . 3 5 2}$ \\
\hline
\end{tabular}




\begin{tabular}{|c|c|c|}
\hline \multicolumn{3}{|c|}{ Process production data } \\
\hline & GELATINE & $\begin{array}{l}\text { CHONDROITIN } \\
\text { SULPHATE }\end{array}$ \\
\hline $\begin{array}{c}\text { Raw material feed to the } \\
\text { system }\end{array}$ & $\begin{array}{c}100 \mathrm{~kg} \text { of fish skins per } \\
\text { batch }\end{array}$ & $\begin{array}{c}25 \mathrm{~kg} \text { of milled cartilage per } \\
\text { batch }\end{array}$ \\
\hline Processing capacity & $200 \mathrm{~kg} /$ day & $75 \mathrm{~kg} /$ day \\
\hline Yield & $\begin{array}{l}\text { Around } \mathbf{1 0 - 1 1} \mathbf{~ k g / d a y ~ o f ~} \\
\text { gelatine ( } 99 \% \text { of purity } \\
\text { after drying+ultrafiltration } \\
\text { steps) are obtained. }\end{array}$ & $\begin{array}{c}\text { Around } \mathbf{2 0 - 2 1} \mathbf{~ k g / d a y ~ o f ~} \\
\text { CS ( } 95 \% \text { of purity after } \\
\text { drying + ultrafiltration steps) } \\
\text { are obtained. }\end{array}$ \\
\hline
\end{tabular}

Table 2 